\title{
A Comparison of Emotion Regulation Strategies of Blind Students With Sighted Students
}

\author{
Samaneh Salimi ${ }^{1 *}$, Esmaeil Mohammadi ${ }^{1}$, Ahmad Sadeghi $^{1}$ \\ 1. Department of Counseling, Faculty of Education and Psychology, University of Isfahan, Isfahan, Iran.
}

Citat on: Salimi S, Mohammadi E, Sadeghi A. A Comparison of Emotion Regulation Strategies of Blind Students With Sighted Students. Iranian Rehabilitation Journal. 2016; 14(2):127-132. https://doi.org/10.18869/nrip.irj.14.2.127

https://doi.org/10.18869/nrip.irj.14.2.127

\section{Article info:}

Received: 03 Feb. 2016

Accepted: 27 May 2016
Keywords:

Blind students, Sighted students, Expressive suppression, Cognitive reappraisal

\begin{abstract}
Objectives: The purpose of the study was to compare the emotion regulation strategies of blind and sighted students.

Methods: The research method used was descriptive and causal-comparative, and the statistical population included all the sighted and blind students at the University of Isfahan and the Islamic Azad University of Khorasgan. The sample volume was 64 members (32 members in each group). Sampling was conducted using the availability sampling method for the first group and the simple random sampling method for the second group. Data was gathered and measured with the help of the Emotion Regulation Scale by O.P. John and J.J. Gross, and analyzed using SPSS 21 and the ANOVA test.
\end{abstract}

Results: The results indicated a significant difference between two groups with regard to applied emotion regulation strategies $(\mathrm{P}<0.05)$; Blind students applied both strategies (cognitive reappraisal and expressive suppression) less. The effect of gender, interaction between gender and vision status was also not significant with respect to emotion regulation $(\mathrm{P}>0.05)$.

Discussion: Emotion regulation is a possible influential factor in many problems that blind people suffer from, more than sighted ones, and using interventions that target emotion regulation strategies would be useful.

\section{Introduction}

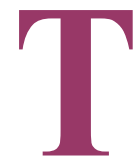

he most noticeable among people afflicted with disabilities are the blind or low sighted. . Blindness and low sightedness are two important health issues in developed and developing countries [1]. According to the World Health Organization, nearly 38 million people are blind worldwide and 110 million have a severe visual im- pairment; the latter's number is increasing [2]. Blindness is not only low sightedness, but is accompanied along with many problems such as the lack of psychological security, basic skills, career goals and job opportunities [3].

Vision loss after illness or an accident causes major changes in lifestyle and habits of the blind person which may cause problems pertaining to psychological adjustment [4], and due to these problems they are subject to

* Corresponding Author:

Samaneh Salimi, PhD Candidate

Address: Department of Counseling, Faculty of Education and Psychology, University of Isfahan, Isfahan, Iran.

Tel: +98 (914) 0346904

E-mail: salimiacademicbox@edu.ui.ac.ir 
more mood disorders compared with their privileged counterparts. For instance, they are more dissociable [5], depressed $[6,7]$ and have lower life quality in comparison with sighted people $[8,9]$, and are generally living facing a constant challenge with regard to psychological and social adjustment.

One of the factors, which was referred to in many of the problems, is the lack of emotion regulation. In fact, emotion regulation is a kind of ability that can equip these people with the use of regulative strategies and then prevent further problems [10]. By emotion regulation, we mean the ability to control experience and the ability to control emotional expression [11]. Emotion regulation contains a range of cognitive, and conscious and unconscious behavioral strategies which are used to maintain or increase excitement [12].

Gross [13] divides emotion regulation strategies into two categories: response-focused strategies and antecedent-focused strategies. Antecedent-focused strategies are used before or in the early stages of responding, while response-focused strategies are related to the behavioral or psychological response management of an emotion.

Two general forms are estimated from among the various ways through which people regulate their emotions. One of them is cognitive reappraisal which is considered to be a kind of cognitive change and is therefore an antecedent-focused emotion regulation. Cognitive reappraisal means the use of unemotional terms and the change of cognition in the interpretation of a position which has the potential to raise an emotion. The second form, which refers to the expression of emotion, is emotional suppression. It pertains to the suppression of emotions and is considered as a response-focused emotion regulation [11].

Previous studies have indicated the role of emotion regulation in a variety of mood disorders such as depression [14] and anxiety [15]. It has also been claimed that a successful performance in social interactions, aggression, impulsive violence, and the sense of shame and guilt are the result of inadequate regulation of emotional responses [16, 28, 29]. Hence, due to a decreased ability to use emotion regulation strategies, the blind suffer more mood disorders than sighted people.

The emotion management of blind people has been studied in terms of emotional intelligence. For example, a study conducted by Hossainian and Emamipur [17] was a comparison of emotional intelligence between blind and sighted male and female students. The study indicated that there is a difference between the two groups' overall emotional intelligence, with the result favoring the sighted students.

Habibi, Khosrojavid and Khanzadeh [18], in a study investigating the effect of teaching emotional intelligence skills on the strategies which help cope with visual impairment in Gilan province, indicated that the attendance of people in emotional intelligence training sessions are affecting the reduction of maladaptive coping strategies with stressor situations. Behpazhooh, Karami nezhad, Ghobaribanab and Shokoohiyekta [19] conducted a study to examine the effect of emotional intelligence and its efficiency on students with visual impairment. Their study concluded that designing emotional intelligence programs can enhance it in students with visual impairment. In a study to probe the effect of emotional intelligence on self-regulation of aggression in people with visual impairment, Eniola [3] said that teaching emotional intelligence is efficient in the reduction of aggression.

The review of the literature indicates that although emotion and its management in blind people have been investigated in the form of emotional intelligence, no study has investigated emotion regulation in this group. The role of emotion regulation has been approved of in a lot of problems and it is likely that differences between the blind and sighted group in dealing with the said problems may be, in part, due to differences between the two groups in using emotion regulation strategies. Thus, this study aims to examine whether there are differences between emotion regulation strategies between blind and sighted subjects.

\section{Methods}

This study is a descriptive, causal-comparative research. The population of this research is composed of two groups: The first group comprises the blind students of Isfahan and Khorasgan Azad University attending the academic year 2014-2015 and the second group consists of the sighted students of Isfahan and Khorasgan Azad University attending the academic year 2014-2015 (the blind students of Isfahan and Khorasgan Azad University were selected as the population because they are the only universities to house centers for the blind among all other Azad universities and public, non-profit universities such as Payame Noor University and the University of Applied Science and Technology).

Sampling was conducted using the available sampling method for the first group and the simple random sampling method for the second group. The number of participants in each group was 32; each group consisted of 19 girls and 13 boys. 
In order to measure emotion regulation in this study, Gross and John's Emotion Regulation Scale [20] was used. This scale consists of 10 items divided into two subscales: reappraisal (6 items) and suppression (4 items). Responses are based on the Likert scale (seven degrees), which range from strongly disagree to strongly agree. High scores on the reappraisal subscale indicate that the individual is capable of interpreting emotionally provocative positions in unemotional terms. High scores on the suppression subscale indicate that the individual suppresses his expression of emotions.

Questions 1, 3, 5, 7, 8 and 10 measure reappraisal and questions 2, 4, 6 and 9 measure suppression. Cronbach's alpha reliability coefficient of this scale in the original version was estimated to be 0.79 for reappraisal and 0.73 for suppression. The Persian volume of Gross and John's Emotion Regulation Questionnaire was normalized by Gasempoor, Elbeigi and Hasanzadeh. The validity of the scale was reported to be desirable, based on internal consistency with an alpha range of 0.60 to 0.81 . Its reliability was obtained through principal component analysis using varimax rotation, the correlation between the subscales $(0.13)$ and criterion validity [21]. Data were analyzed using statistical software such as SPSS 21 and the ANOVA test.

\section{Results}

Descriptive statistics' findings, including mean and standard deviation, are provided in Table 1. As seen in Table 1 , the results of descriptive statistics indicate the high use of emotion regulation strategies among the sighted group. Also, girls use the reappraisal strategy more than boys, but boys are superior in using the emotional suppression strategy. Then, to determine the significance of these differences, analysis of variance was used whose results are presented in Table 2. Homogeneity of variances in the two groups and the normal distribution of sample data are

Table 1. Descriptive statistics of emotion regulation strategies in two groups of blind and sighted students.

\begin{tabular}{|c|c|c|c|c|c|}
\hline Variables & Subjects & Gender & $\mathbf{N}$ & Mean & SD \\
\hline \multirow{9}{*}{ Reappraisal } & & Girl & 19 & 32.84 & 3.166 \\
\hline & Blind & Boy & 13 & 31.92 & 4.609 \\
\hline & & Total & 32 & 32.46 & 3.775 \\
\hline & & Girl & 19 & 35.73 & 4.420 \\
\hline & Sighted & Boy & 13 & 33.76 & 4.657 \\
\hline & & Total & 32 & 34.93 & 4.550 \\
\hline & & Girl & 19 & 34.28 & 4.066 \\
\hline & Total & Boy & 13 & 32.84 & 4.636 \\
\hline & & Total & 32 & 33.70 & 4.330 \\
\hline \multirow{9}{*}{$\begin{array}{l}\text { Emotional suppres- } \\
\text { sion }\end{array}$} & & Girl & 19 & 19.00 & 3.055 \\
\hline & Blind & Boy & 13 & 20.92 & 3.277 \\
\hline & & Total & 32 & 19.78 & 3.240 \\
\hline & & Girl & 19 & 21.15 & 3.077 \\
\hline & Sighted & Boy & 13 & 22.00 & 3.135 \\
\hline & & Total & 32 & 21.50 & 3.079 \\
\hline & & Girl & 19 & 20.07 & 3.216 \\
\hline & Total & Boy & 13 & 21.46 & 3.190 \\
\hline & & Total & 32 & 20.64 & 3.253 \\
\hline
\end{tabular}


Table 2. The results of variance analysis in the subscales of reappraisal and suppression.

\begin{tabular}{cccccccc}
\hline Variables & Source of Changes & Sum of Squares & df & Mean Square & F & Sig. & Eta \\
\hline \multirow{2}{*}{ Reappraisal } & Vision state & 86.743 & 1 & 86.743 & 4.969 & 0.030 & 0.076 \\
& Gender & 32.159 & 1 & 32.159 & 1.842 & 0.180 & 0.030 \\
& Vision state*gender & 4.243 & 1 & 4.243 & 0.243 & 0.624 & 0.004 \\
Suppression & Vision state & 40.385 & 1 & 40.385 & 4.139 & 0.046 & 0.065 \\
& Gender & 29.510 & 1 & 29.510 & 3.024 & 0.087 & 0.048 \\
& Vision state*gender & 4.510 & 1 & 4.510 & 0.462 & 0.499 & 0.008 \\
\hline
\end{tabular}

two of the most assumptions of covariance analysis. The Levene, and the Kolmogorov-Smirnov tests were used to assess the assumptions respectively.

The values of the Kolmogorov-Smirnov test for reappraisal are $(\mathrm{k}-\mathrm{s}-\mathrm{Z}=0.105, \mathrm{P}=0.074)$ and suppression $(\mathrm{k}-\mathrm{s}$ $\mathrm{z}=0.11, \mathrm{P}=0.054)$ indicate the normal distribution of sample data. The values of the Levene test for reappraisal $(\mathrm{F}=0.51$, $\mathrm{P}=0.67)$ and suppression $(\mathrm{F}=0.013, \mathrm{P}=0.99)$ also indicate the homogeneity of variances in the two groups.

As seen in Table 2, the results of variance analysis indicate that the value of $\mathrm{F}$ has a significant difference between the blind and sighted groups with respect to using the reappraisal strategy $(\mathrm{P}<0.05)$. Also, according to the estimated Eta square of $E t a=0.07$, it can be said that $7 \%$ of the difference between these two groups is due to the state of vision. Likewise, the value of $\mathrm{F}$ has a significant difference between the blind and sighted groups with respect to using the suppression strategy $(\mathrm{P}<0.05)$. And, according to the estimated Eta square of Eta $=0.06$, it can be said that $6 \%$ of the difference between these two groups is due to the state of vision. Sex and the interaction between gender and state of vision does not lead to a significant difference $(\mathrm{P}>0.05)$ between the two groups in terms of the type of strategy used.

\section{Discussion}

A variety of disabilities including visual impairment is followed by different psychological reactions, and often cause mental crisis through depression, anxiety, decreased self-esteem and other psychological problems [22]. Keeping in mind the role of emotional regulation in depression [14], anxiety [15] and other emotional problems [16], it seems that helping people to improve emotion regulation strategies is essential, and is necessary to explore whether emotion regulation strategies in blind people are different from those of the sighted people? This study was conducted in order to serve that very purpose and it is probably the first endeavor of its kind.

The results of the present study indicated that there is a significant difference between the two groups when it came to using the reappraisal strategy, with the sighted group using it more. This result is consistent with the results of the study conducted by Hossainian and Emamipur [17] who indicated that blind students have lower levels of emotional intelligence than sighted students.

This result is also similar to the findings of Najati [23] who demonstrated that the cognitive performance of blinds veterans was lower tin comparison with sighted veterans. Accurate and rapid visual information are essential for cognitive functions [23], and the sense of sight as a major source of human knowledge helps the individual to obtain information from a distance. When one considers the reappraisal of rapid change of cognition, we can say that the lack of vision leads to a lack of data to assess the situation from the other's perspective [24].

The results of variance analysis indicated a significant difference between the two groups in using the suppression strategy too. The blind group used it less. Considering that impulse control is a kind of emotional suppression, the result is consistent with the findings of Hossainian and Emamipur [17] who indicated that blind people are less able to control their impulses. Blind people indicate more visible facial gestures compared with sighted people which could be due to the former's inability to effectively use emotion regulation strategies [25]. Perhaps the inability of these people in observing the emotions of others in emotional situations does not allow them to suppress their emotions. They indicate their emotions to the other person to know how they feel now. 
The results also indicate no significant difference between gender and the interaction between gender and the state of vision in both emotion regulation strategies. This result is consistent with the findings of Ghoreyshi Rad [26] who said that there is no significant difference between both sexes in relation to identity state, coping strategy and depression. Probably due to the limited number of blind schools, those attending such institutions belong to a mixed group. This leads to mutual learning, including emotion regulation strategies.

In short, the difference between the two groups in terms of using both reappraisal and emotional suppression strategies are significant, and the sighted group is superior in this regard. Thus, emotion regulation can be certainly considered as one of the factors underlying the many problems plaguing blind people. For example, although being a blind person in a position where he is faced with difficulty in navigation leads to anxiety, it is probably due to his lack of ability to manage feelings of anxiety that reduces his effectiveness. Comparably, sighted people face a lot more situations which cause them anxiety.

On the one hand, the negative emotions such as sadness, anxiety and helplessness in addressing these emotions after encountering a sighted born person with a great loss such as blindness is undeniable and possibly deficiency of these people in using the effective emotion regulation strategy is one of the most important reasons for problems such as psychological compatibility, depression and anxiety after the onset of blindness.

On the other hand, compatibility with any type of disability, including blindness does not simply occur and considering the role of emotion regulation in psychological adaptation and resilience, the lack of effective emotion regulation skills can be a major factor in psychological adjustment problems these people knew at the beginning of disability.

Finally it is noteworthy that disabled people have difficulty in expressing their intentions and it affects their emotions, so the use of technologies such as glass interface helps physical disabled people to communicate with environment and facilitate understanding of their intentions [27], in visual disability such innovations allow blind person use obtained information for better regulation of their own emotions by establishing intercommunication between blind person and environment.

The study was faced with some limitations, including the lack of vision of the people forming a part of the study group and the use of availability sampling method in the blind group. The latter limitation makes generalization of results an exercise that would require considerable caution.

\section{Conclusion}

Efforts to modify the strategies used by blind people are very important. Therefore, conducting studies to explore the factors affecting the use of these strategies as well as trying to identify the best therapeutic interventions should be a priority for future researchers.

\section{Acknowledgements}

At the end, we thank all the respected authorities of the Blinds Center at the University of Isfahan and all the blind subjects who helped us in this research. The current research hasn't received any financial support

\section{Conflict of Interest}

The authors declared no conflict of interests.

\section{References}

[1] Ramezani A, Pardis M, Rafati N, Kazemi-Moghaddam M, Katibeh M, Rostami P, et al. Causes of visual impairment among patients referred to a visual rehabilitation clinic in Iran. Korean Journal of Ophthalmology. 2012; 26(2):80-83. doi: 10.3341/kjo.2012.26.2.80

[2] Taylor HR, Keeffe JE. World blindness: a $21^{\text {st }}$ century perspective. British Journal of Ophthalmology. 2001; 85(3):26166. doi: 10.1136/bjo.85.3.261

[3] Eniola MS. The influence of emotional intelligence and selfregulation strategies on remediation of aggressive behaviours in adolescent with visual impairment. Ethno-Med. 2007; 1(1):71-77.

[4] Foxall MJ, Barron CR, von Dollen K, Jones PA, Shull KA. Predictions of loneliness in low vision adults. Western Journal of Nursing Research. 1992; 14:86-89. doi: $10.1177 / 019394599201400107$

[5] Green J, Siddall H, Murdoch I. Learning to live with glaucoma: a qualitative study of diagnosis and the impact of sight loss. Social Science \& Medicine. 2002; 55(2):257-67. doi: 10.1016/s0277-9536(01)00169-1

[6] Stelmack J. Quality of life of low-vision patients and outcomes of low-vision rehabilitation. Optometry \& Vision Science. 2001; 78(5):335-42. doi: 10.1097/00006324-20010500000017

[7] Horowitz A, Reinhardt JP, Boerner K, Travis LA. The influence of health, social support quality and rehabilitation on depression among disabled elders. Aging \& Mental Health. 2003; 7(5):342-50. doi: 10.1080/1360786031000150739 
[8] Lamoureux EL, Hassell JB, Keeffe JE. The impact of diabetic retinopathy on participation in daily living. Archives of Ophthalmology. 2004;122(1):84-88. doi: 10.1001/archopht.122.1.84

[9] Chia EM, Wang JJ, Rochtchina E, Smith W, Cumming RR, Mitchell P. Impact of bilateral visual impairment on healthrelated quality of life: the Blue Mountains Eye study. Investigative Ophthalmology \& Visual Science. 2004; 45(1):71-76. PMID: 14691156

[10] Baurain C, Nader-Grosbois N. Socio-emotional regulation in children with intellectual disability and typically developing children in interactive contexts. ALTER-European Journal of Disability Research. 2012; 6(2):75-93. doi: 10.1016/j. alter.2012.02.001

[11] Gross JJ. Emotion regulation: Affective, cognitive, and social consequences. Psychophysiology. 2002; 39(3):281-91. doi: $10.1017 /$ s0048577201393198

[12] Gross JJ. Emotion regulation in adulthood: Timing is everything. Current Directions in Psychological Science. 2001; 10(6):214-19. doi: 10.1111/1467-8721.00152

[13] Gross JJ. Antecedent-and response-focused emotion regulation: divergent consequences for experience, expression, and physiology. Journal of Personality \& Social Psychology. 1998; 74(1):224-237. doi: 10.1037//0022-3514.74.1.224

[14] Abbott BV. Emotion dysregulation and re-regulation: predictors of relationship intimacy and [PhD dissertation]. Texas: Texas A\&M University; 2005.

[15] Beauregard M, Levesque J, Bourgouin P. Neural correlates of conscious self-regulation of emotion. Journal of Neuroscience. 2001; 21(18):165. PMID: 11549754

[16] Stegall SD. Adolescent emotional development: Among shame and guilt proneness, emotion regulation, and psychopathology [PhD dissertation]. Maine: University of Maine; 2004.

[17] Hossainian S, Emamipur S. [Comparing emotional intelligence and assertiveness in normal and blind students (Persian)]. Applied Psychology. 2007; 1:19-29.

[18] Habibi Z, Khosrojavid M, Khanzadeh H. [Efficacy of emotional intelligence training on coping strategies with stress in individual with visual impairments (Persian)]. Holistic Nursing \& Midwifery. 2014; 24(71):21-29.

[19] Behpazhooh A, Karami nezhad R. Ghobari-Banab B, Shokoohi-Yekta M. [Emotion intelligence training and its effectiveness on students with visual impairment (Persian)] Psychology of Exceptional Individuals. 2013; 3(10):1-20.

[20] Gross JJ, John OP. Individual differences in two emotion regulation processes: Implications for affect, relationships, and well-being. Journal of personality and social psychology. 2003; 85(2):348-62. doi: 10.1037/0022-3514.85.2.348

[21] Mashhadi A, Gasempoor A, Akbari E, ElBeigi R, Hasanzadeh $\mathrm{S}$. [The role of anxiety sensitivity and emotion regulation in prediction of students social anxiety disorder (Persian)]. Knowledge Research Applied Psychology. 2013; 14(2):89-99.

[22] Abbasi Tehrani F, Dolatabadi S. [Analysis of the amount of Depression and Anxiety in 16-50 year old visual disabled in Tehran (Persian)]. Journal of Exceptional Children. 2002; 6:359-376.
[23] Sacks SZ. Teaching social skills to young children with visual impairments. In: Sacks SZ, Wolffe KE, editors. Teaching Social Skills to Students with Visual Impairments: From Theory to Practice. New York: American Foundation for Blind; 2006, p. 145-72.

[24] Nejati V. [Comparison of cognitive status of blind veterands with sighted people (Persian)]. Journal of Military Medicine. 2008; 10(1):21-28.

[25] Papadopoulos K, Metsiou K, Agaliotis I. Papadopoulos K, Metsiou K, Agaliotis I. Adaptive behavior of children and adolescents with visual impairments. Research in Developmental Disabilities. 2011. 32(3):1086-096. doi: 10.1016/j. ridd.2011.01.021

[26] Ghoreyshi Rad F. [Identity status, adjustment strategies and depression in visually impaired adolescents (Persian)] Journal of Exceptional Children. 2011; 12(4):41-54.

[27] Mahnam A. Development of a wearable human-computer interface based on electro-oculogram for assisting disabled people. Journal of Rehabilitation. 2014. 14(4):113-24.

[28] Massah O, Sohrabi F, Azami Y, Doostian Y, Farhoudian A. Effectiveness of gross model-based emotion regulation strategies training on anger reduction in drug-dependentindividuals and its sustainability in follow-up. International Journal of High Risk Behaviors \& Addiction. 2016; 5(1):e24327.

[29] Choopan H, Kalantarkousheh SM, Aazami Y, Doostian Y Farhoudian A, Massah O. Effectiveness of emotion regulation training on the reduction of craving in drug abusers. Addiction \& Health. 2016; 8(2):68-75. 